\title{
Study on Mechanical Properties and Damage Characteristics of Red Sandstone under Freeze-thaw and Load
}

\author{
Lei Shi, ${ }^{1,2}$ Yang Liu, ${ }^{2}$ Xiangzhen Meng $\mathbb{D}^{3},{ }^{3}$ and Huimei Zhang $\mathbb{D}^{3}$ \\ ${ }^{1}$ China Coal Research Institute, Beijing 100013, China \\ ${ }^{2}$ CCTEG Xi'an Research Institute, Xi'an 710054, China \\ ${ }^{3}$ College of Architecture and Civil Engineering, Xi'an University of Science and Technology, Xi' an 710054, China \\ Correspondence should be addressed to Xiangzhen Meng; 18104053009@stu.xust.edu.cn
}

Received 29 September 2020; Revised 5 May 2021; Accepted 7 June 2021; Published 19 June 2021

Academic Editor: Tayfun Dede

Copyright (@ 2021 Lei Shi et al. This is an open access article distributed under the Creative Commons Attribution License, which permits unrestricted use, distribution, and reproduction in any medium, provided the original work is properly cited.

\begin{abstract}
To analyze the effects of freeze-thaw cycles and confining pressure on the mechanical properties of red sandstone, through freezethaw cycles and triaxial compression tests, full stress-strain curves of different freeze-thaw cycles and different confining pressures were obtained. The degradation degree of red sandstone was quantitatively considered from different mechanical parameters of ultimate stress, elastic modulus, and Poisson's ratio. Based on summarizing the characteristics of rock under freeze-thaw and load, the total damage variable of rock was determined by the reasonable measurement of freeze-thaw damage variable and load damage variable, and a damage constitutive model under freeze-thaw and load was established. The research showed that the freeze-thaw cycles aggravate the degree of rock damage deterioration, the rock stiffness and strength were reduced, and the characteristics of plastic deformation and ductile failure were more obvious. The confining pressure inhibited red sandstone internal damage, and with the increase of confining pressure, the stiffness and strength and the plastic characteristics were increased. In the overall trend, the mechanical parameters had different sensitivity to the degradation effect of freeze-thaw cycles and confining pressure. Regardless of the increase in the number of freeze-thaw cycles or confining pressure, the strain softening modulus tended to decrease gradually, and red sandstone plastic damage became more obvious after the stress peak. The total damage evolution path of red sandstone reflected the nonlinear influence of freeze-thaw and load on the total damage propagation. The research results provide theoretical support for the improvement of the technology of the effluent coal rock in Balasu Coal Mine.
\end{abstract}

\section{Introduction}

With the continuous development of economic globalization, the number and scale of cold regions engineering construction are gradually increasing. The freeze-thaw disaster will be the primary problem affecting cold regions construction. Therefore, studying the damage characteristics and failure mechanism of rock under freezing and thawing has important theoretical and engineering significance to guarantee the safety of construction projects.

In recent years, many scholars at home and abroad have started to explore the rocks mechanical properties by different rocks types, setting different freeze-thaw temperatures or freeze-thaw times, using different chemical solutions as the freeze-thaw medium, systematically investigate the effects of freeze-thaw on rock mechanical properties, and made a lot of achievements. Ma et al. [1] used computational fluid dynamics to quantitatively analyze the migration characteristics of water-sand two-phase flow in fractured rock mass. Khanlari and Abdilor [2] studied the effect of freeze-thaw cycles on sandstone mechanical properties. Demirdag et al. [3] studied the effects of freeze-thaw cycles on saturated and unsaturated limestone physical and mechanical properties and compared the corresponding mechanical parameters. Ma et al. [4] conducted a series of experiments to study the influence of erosion and seepage on the hydraulic properties of broken red sandstone. Karaca et al. [5] divided 10 rocks into different groups to measure the amount of rock wear before and after freeze-thaw cycle. Huseyin [6] and Bayram [7] measured the uniaxial 
compressive strength, wave velocity, and other mechanical parameters of andesite under the action of freeze-thaw environment. Momeni et al. [8], Li et al. [9] discussed the effects of freeze-thaw cycles on the mechanical properties of granite. Ghobadi and Babazadeh [10] explored the trends of sandstone weight and other characteristics under different freeze-thaw cycles. Khanlari et al. [11] selected five different types of sandstones to explore the effects of freeze-thaw cycles on the mechanical properties of rocks. Jihwan et al. [12] discussed the mechanical properties of three kinds of rocks, basalt, diorite, and tuff, in freeze-thaw environment. Liu et al. [13], Zhou et al. [14], Wen et al. [15] used red sandstone, granite porphyry, and limestone to conduct freeze-thaw cycles experiments and systematically studied the physical and mechanical properties of rocks. Luo et al. [16] studied the failure characteristics of diabase under the action of freeze-thaw cycles. Eslami et al. [17] conducted freeze-thaw tests on five saturated rock samples under natural conditions and monitored rocks weathering evolution by measuring different physical parameters. Yu et al. [18] and $\mathrm{Yu}$ et al. [19] studied the effects of freeze-thaw cycles on sandstone mechanical properties under triaxial compression conditions. Chen et al. [20] set the freeze-thaw temperature at $-18^{\circ} \mathrm{C}-0^{\circ} \mathrm{C}$, and Tan et al. [21] set the freezethaw temperature at $-40^{\circ} \mathrm{C}-40^{\circ} \mathrm{C}$, and they both studied the rock mechanical properties under uniaxial compression. Chen et al. [22] selected the freeze temperature at $-20^{\circ} \mathrm{C}$ and melting temperature at $65^{\circ} \mathrm{C}, 100^{\circ} \mathrm{C}$, and $400^{\circ} \mathrm{C}$, through the uniaxial compression test, to study the damage degree in granite. Wen et al. [23] analyzed the changes of physical parameters of saturated granite in four temperature ranges $\left(-10^{\circ} \mathrm{C} \sim 20^{\circ} \mathrm{C},-20^{\circ} \mathrm{C} \sim 20^{\circ} \mathrm{C},-30^{\circ} \mathrm{C} \sim 20^{\circ} \mathrm{C}\right.$, and $\left.-40^{\circ} \mathrm{C} \sim 20^{\circ} \mathrm{C}\right)$. Gao et al. [24], Ding et al. [25], Han et al. [26], Fang et al. [27], and $\mathrm{Ni}$ et al. [28] considered the effects of rock erosion and freeze-thaw damage on the rock and conducted mechanical tests on the number of different freeze-thaw cycles in different chemical solutions. The damage characteristics of rock under this condition were studied.

In addition, some scholars study the effects of freezethaw cycles on rock failure characteristics through functions or damage constitutive relations. Fatih [29] determined the uniaxial compressive strength function of limestone under freeze-thaw conditions. Cheng et al. [30] established a damage evolution and prediction model based on reliability and damage theory to better analyze the internal degradation of materials. Tan et al. [31] studied the freeze-thaw resistance of the material by using the complex master curve of the established generalized sigmoidal model. Yuan et al. [32] determined the constitutive model of frozen-thawed rock based on the mesoscopic damage model of intact rock. Based on elastoplastic theory and fatigue damage mechanics, Liu et al. [33] proposed a model for describing compressive strength under freeze-thaw. Zhang and Yang [34], Zhou et al. [35], and Huang et al. [36] used static elastic modulus method to characterize rock freeze-thaw damage and assumed that the microelement strength satisfies the Weibull distribution, and the loading damage is obtained by statistical theory. On this basis, statistical constitutive equations under freeze-thaw and load were determined.
Although there have been many studies on cold region rocks, most of them were directed to the mechanical properties of rocks, and there were few studies on the influence of freezing-thawing and confining pressure on the rock through quantitative analyzing the change trend of mechanical parameters. The studies of cold region rocks were dominated by uniaxial conditions, and the researches under confining pressure were relatively scarce, but the complete destruction of rocks still had the bearing characteristics, which cannot be reflected by uniaxial tests. Furthermore, the related aspect's theoretical research of frozen-thawed rock damage constitutive relationship was particularly lacking. In this paper, Shaanxi red sandstone was selected for the study of freeze-thaw cycles and conventional triaxial compression test. The deterioration degree and the softening modulus were further obtained by the mechanical parameters. The stress-strain curves were obtained from the test data. The effects of freeze-thaw cycles and confining pressure on the damage characteristics of red sandstone were analyzed by the established constitutive relation.

\section{Test and Result Analysis}

2.1. Freeze-Thaw Cycle and Triaxial Compression Test. The experimental process and methodology are provided in a schematic flowchart, as shown in Figure 1.

The design test steps were as follows.

(1) We selected fresh and unbroken red sandstone from the project site, and the red sandstone was machined into cylindrical standard specimens with a diameter of $50 \mathrm{~mm}$ and a height of $100 \mathrm{~mm}$.

(2) To reduce the discreteness of the test results, the specimens with obvious defects on the surface were removed, and then, the specimens with similar longitudinal wave velocities were selected by the acoustic velocity meter to ensure the similarity of the internal structure of rock.

(3) The selected specimens were placed in an oven at a temperature of $105^{\circ} \mathrm{C}$ to $110^{\circ} \mathrm{C}$ for high-temperature baking until the specimens quality did not change (the quality of the specimens did not exceed $0.1 \%$ ).

(4) The dry specimens were placed in a vacuum vessel, and the vessel was evacuated by a pressure of $-0.1 \mathrm{MPa}$. After continuously extracting air in the vessel for two hours, a certain amount of distilled water was added to the vessel. Then, drawing air was continued for four hours until there were no more bubbles in the water. Finally, the specimens were soaked in water for more than 24 hours to saturation.

(5) The freeze-thaw test instrument was American XTM605 rapid freeze-thaw test machine. The temperature was controlled by a thermistor sensor, and the temperature control precision was $\pm 0.2^{\circ} \mathrm{C}$. The vacuum saturated specimens were placed in a rapid freeze-thaw test machine, and the freeze-thaw cycle test was performed 0 times, 5 times, 10 times, 20 


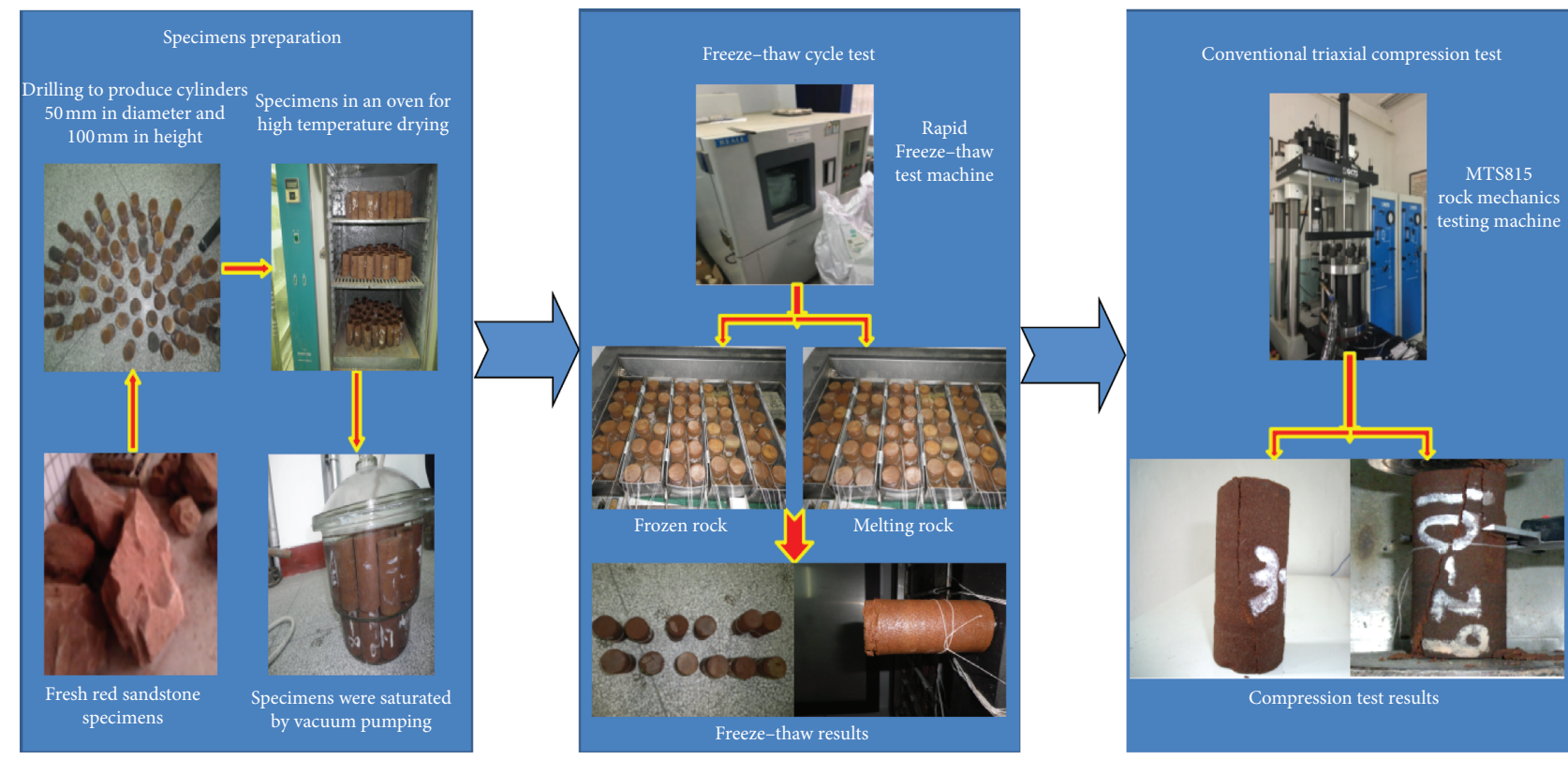

FIgURE 1: The freeze-thaw and conventional triaxial compression test process in a schematic flowchart.

times, and 40 times, respectively. The temperature of the freeze-thaw tester was $-20^{\circ} \mathrm{C} \sim 20^{\circ} \mathrm{C}$, which was essentially a temperature drop from $+20^{\circ} \mathrm{C}$ to $-20^{\circ} \mathrm{C}$ and then rise to $+20^{\circ} \mathrm{C}$ as a freeze-thaw cycle, and each freeze-thaw cycle was controlled for 12 hours.

(6) After the specimens' freeze-thaw cycle, the MTS815 electrohydraulic triaxial servo tester was used to perform the triaxial compression test with confining pressures of $0 \mathrm{MPa}, 2 \mathrm{MPa}, 4 \mathrm{MPa}$, and $6 \mathrm{MPa}$, respectively.

2.2. Stress-Strain Characteristic Analysis. Through freezethaw cycle and triaxial compression tests, the full stressstrain test curves of red sandstone triaxial compression test under different freeze-thaw cycles were obtained, as shown in Figure 2. It can be seen that as the number of freezethaw cycles increases, the deformation modulus of red sandstone decreased, the stress-strain compressibility was increased, and the peak point of stress-strain curve decreased. However, the strain corresponding to the peak point increased, while the softening stage after the peak tended to be gentle, and the residual strength after complete failure decreased, indicating that freeze-thaw cycles exacerbated sandstone damage. With the increase of confining pressure, the deformation modulus of sandstone increased, the stress-strain compressibility decreased, the peak point of the stress-strain curve, and the strain corresponding to the peak point increased, the postpeak softening stage tended to be gentle, and the residual strength after complete failure increased, indicating that the confining pressure caused the internal damage of red sandstone to be suppressed.

\section{Analysis of Red Sandstone Mechanical Parameters}

3.1. Effect of Freeze-Thaw Cycles on Mechanical Parameters of Red Sandstone. In order to better analyze the influence of freezing-thawing on sandstone, the reduction of physical parameters under the action of freezing-thawing cycles and confining pressure was defined as deterioration degree. Then, when the confining pressure was constant, for each freeze-thaw cycle, the total deterioration degree $C_{w n}$ can be expressed as

$$
C_{w n}=\frac{Z_{w 0}-Z_{w n}}{Z_{w 0}} \times 100 \%
$$

where $Z_{w 0}$ was the value of mechanical parameters when confining pressure $w \mathrm{MPa}(w=0,2,4,6)$ and freeze-thaw cycles equaled 0 times; $Z_{w n}$ was the value of mechanical parameters when confining pressure $w \mathrm{MPa}$ and freeze-thaw cycles equaled $n$ times $(n=0,5,10,20,40)$.

According to test data and (1), the deterioration degree of red sandstone under different freeze-thaw cycles by mechanical parameters can be obtained, and the results are shown in Table 1.

It can be seen from Table 1 that, under the action of freeze-thaw cycles, the difference in deterioration degree obtained by different mechanical parameters was relatively large. When the confining pressure was constant, as the freeze-thaw cycles increase, the deterioration degrees obtained by the extreme stress and elastic modulus were gradually increased. As the freeze-thaw cycles increase, the rock damage was intensified, and the deformation was also increased, resulting in an increase in Poisson's ratio. Therefore, the deterioration degree obtained by Poisson's 

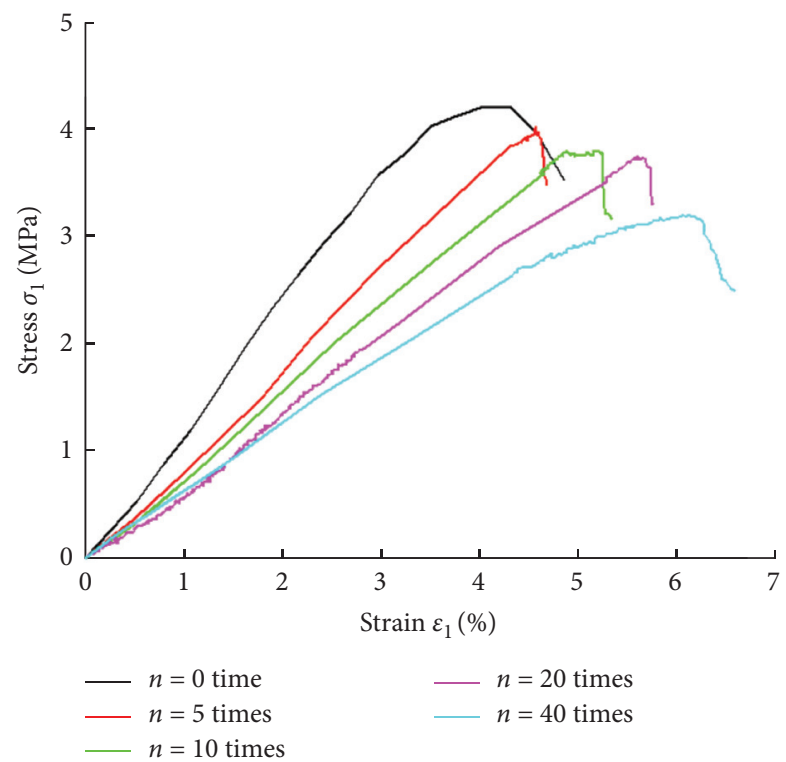

(a)

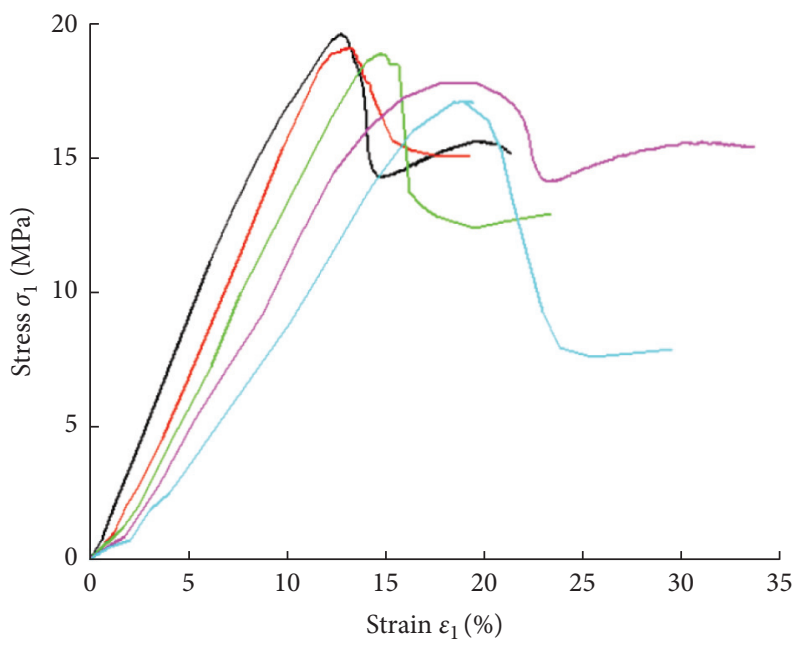

$n=0$ time
$n=5$ times
$n=10$ time $n=20$ times

$n=40$ times

(c)

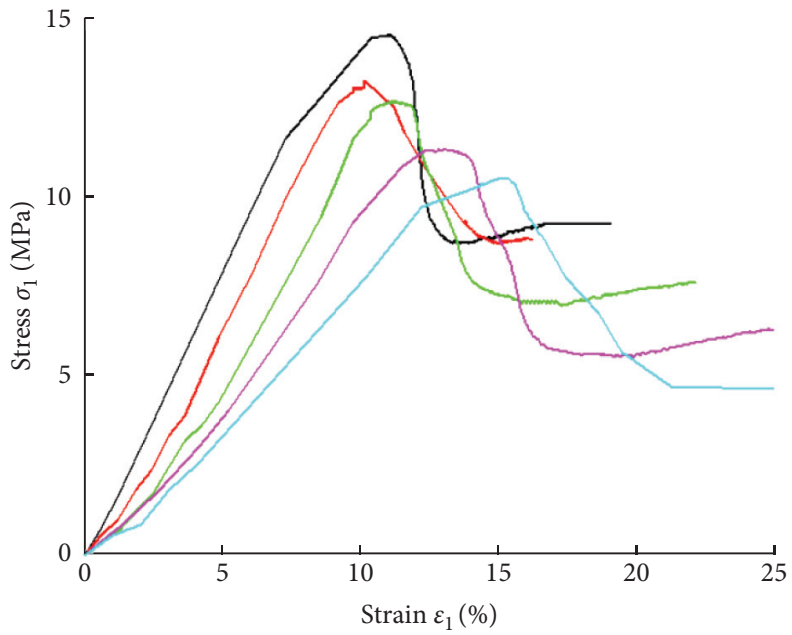

- $n=0$ time

- $n=5$ times

- $n=10$ times

- $n=20$ times

$n=40$ times

(b)

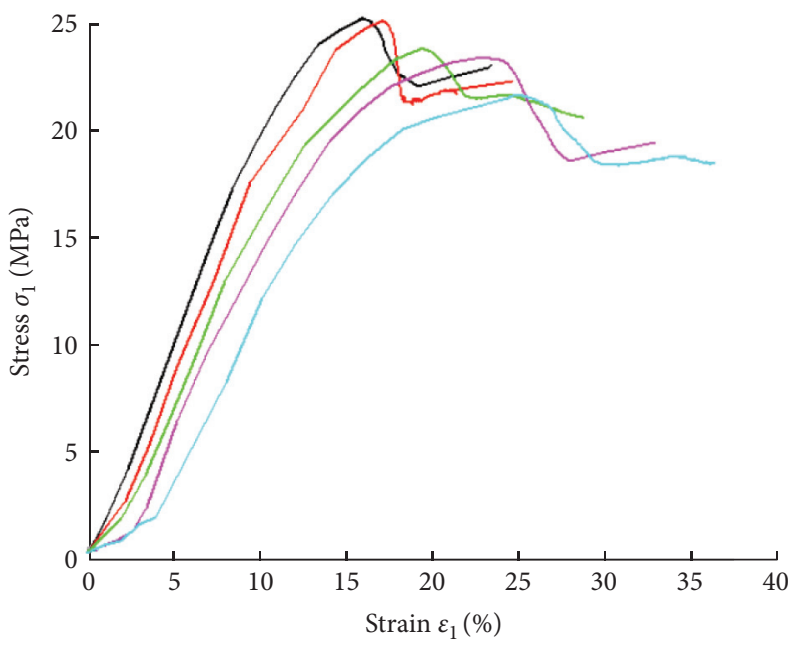

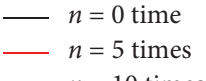

$n=20$ times

$n=40$ times

(d)

FIGURE 2: Full stress-strain curves of red sandstone triaxial compression test under different freeze-thaw cycles. (a) $\sigma_{3}=0 \mathrm{MPa}$. (b) $\sigma_{3}=2 \mathrm{MPa}$. (c) $\sigma_{3}=4 \mathrm{MPa}$. (d) $\sigma_{3}=6 \mathrm{MPa}$.

TABLE 1: Deterioration degree of red sandstone mechanical parameters under different freeze-thaw cycles.

\begin{tabular}{|c|c|c|c|c|}
\hline \multirow{2}{*}{ Confining pressure } & \multirow{2}{*}{ Freeze-thaw cycles times } & \multicolumn{3}{|c|}{ Deterioration degree $C_{n}(\%)$} \\
\hline & & Extreme stress (MPa) & Elastic modulus (GPa) & Poisson's ratio \\
\hline \multirow{5}{*}{0} & 0 & 0 & 0 & 0 \\
\hline & 5 & 4.96 & 31.19 & -3.07 \\
\hline & 10 & 10.17 & 39.60 & -4.23 \\
\hline & 20 & 11.37 & 58.33 & -7.31 \\
\hline & 40 & 21.96 & 59.13 & -7.69 \\
\hline \multirow{5}{*}{2} & 0 & 0 & 0 & 0 \\
\hline & 5 & 10.09 & 6.63 & -0.39 \\
\hline & 10 & 10.34 & 21.43 & -1.55 \\
\hline & 20 & 14.28 & 35.83 & -3.88 \\
\hline & 40 & 21.42 & 48.81 & -7.36 \\
\hline
\end{tabular}


TABLE 1: Continued.

\begin{tabular}{|c|c|c|c|c|}
\hline \multirow{2}{*}{ Confining pressure } & \multirow{2}{*}{ Freeze-thaw cycles times } & \multicolumn{3}{|c|}{ Deterioration degree $C_{n}(\%)$} \\
\hline & & Extreme stress $(\mathrm{MPa})$ & Elastic modulus (GPa) & Poisson's ratio \\
\hline \multirow{5}{*}{4} & 0 & 0 & 0 & 0 \\
\hline & 5 & 2.65 & 10.81 & -0.78 \\
\hline & 10 & 3.78 & 20.82 & -1.96 \\
\hline & 20 & 7.89 & 34.52 & -3.53 \\
\hline & 40 & 12.87 & 43.76 & -7.06 \\
\hline \multirow{5}{*}{6} & 0 & 0 & 0 & 0 \\
\hline & 5 & 2.09 & 5.09 & -0.39 \\
\hline & 10 & 5.42 & 19.65 & -1.97 \\
\hline & 20 & 7.50 & 24.80 & -2.36 \\
\hline & 40 & 11.25 & 43.48 & -5.91 \\
\hline
\end{tabular}

ratio was negative. The deterioration degree obtained by different mechanical parameters further indicated that the increase of freeze-thaw cycles leaded to the rock damage aggravated. However, the deterioration degree obtained by the elastic modulus was faster, the extreme stress was second, and the Poisson's ratio was the slowest. It can be seen that the sensitivity of sandstone mechanical parameters to the freezethaw cycle degradation effect is as follows: elastic modulus $>$ extreme stress $>$ Poisson's ratio.

\subsection{Effect of Confining Pressure on Mechanical Parameters of} Red Sandstone. In order to better analyze the influence of confining pressure on sandstone, the reduction of physical parameters under the action of confining pressure was defined as the deterioration degree. Then, when freeze-thaw cycle was constant, for each confining pressure, total deterioration degree $C_{w n}$ can be expressed as

$$
C_{w n}=\frac{Z_{0 n}-Z_{w n}}{Z_{0 n}} \times 100 \%
$$

where $Z_{0 n}$ was the value of mechanical parameters when confining pressure $0 \mathrm{MPa}$ and freeze-thaw cycles equaled $n$ times $(n=0,5,10,20,40)$.

According to test data and (2), the deterioration degree of red sandstone under different confining pressure by mechanical parameters can be obtained, and the results are shown in Table 2.

It can be seen from Table 2 that since the confining pressure suppressed the lateral deformation and the damage inside the sandstone, the mechanical properties were improved, so the sandstone compressive strength and elastic modulus increase with the increase of the confining pressure, resulting in the deterioration degree obtained, thereby having a negative growth trend. Poisson's ratio obtained by longitudinal deformation and lateral deformation gradually reduced, resulting in the deterioration degree obtained, thereby having a growth trend. Under the same freeze-thaw times, the deterioration degree absolute value obtained by different mechanical parameters gradually increases with the increase of confining pressure, but the overall increase slowed down, indicating that the the influence magnitude of confining pressure on the mechanical properties of sandstone gradually decreased with the increase of confining pressure. The deterioration degree obtained by the extreme stress was faster, the elastic modulus was second, and Poisson's ratio was the slowest. It can be seen that the sensitivity of sandstone mechanical parameters to the confining pressure degradation effect is as follows: extreme stress $>$ elastic modulus $>$ Poisson's ratio.

\subsection{Effects of Freeze-Thaw and Confining Pressure on Postpeak} Softening Characteristics of Red Sandstone. When the number of freeze-thaw cycles was constant, the rate of curve decline after stress-strain peak was gradually slowing down with the increase of confining pressure. When confining pressure was constant, the curve after stress-strain peak gradually became gentle with the increase of freeze-thaw cycles. In order to quantitatively consider strain softening degree after sandstone peak under different confining pressures and different freeze-thaw cycles, the strain softening modulus was defined as

$$
R=\frac{\sigma_{s c}-\sigma_{r}}{\varepsilon_{r}-\varepsilon_{s c}}
$$

where $\sigma_{s c}$ and $\varepsilon_{s c}$ were extreme stress and extreme strain; $\sigma_{r}$ and $\varepsilon_{r}$ were residual stress and the corresponding strain when the residual stress was just reached; $R$ was the strain softening modulus. The larger the $R$, the steeper the curve after peak, and the more pronounced the strain softening, that is, the more brittle the damage after stress peak. When $\varepsilon_{u} \longrightarrow \varepsilon_{s c}, R \longrightarrow \infty$, rock was completely brittle failure.

The crack points were different when the rock reached residual strength under different confining pressures and freeze-thaw cycles. Through the test curves of Figure 2 and (3), the strain softening curve after stress-strain peak under different confining pressures and freeze and thaw cycles can be obtained, as shown in Figures 3 and 4 .

It can be seen from Figures 3 and 4 that, in the general trend, since the confining pressure had the effect of inhibiting rock damage, with the increase of confining pressure, the strain softening modulus was decreased, and the plastic damage of rock became more and more obvious. With the increase of freeze-thaw cycles, the strain softening modulus was decreased with the increase of freeze-thaw damage variable. It can be seen that the freeze-thaw cycles aggravate rock damage and lead to enhancing its plastic. 
TABLE 2: Deterioration degree of sandstone mechanical parameters under different confining pressures.

\begin{tabular}{|c|c|c|c|c|}
\hline \multirow{2}{*}{ Freeze-thaw cycles times } & \multirow{2}{*}{ Confining pressure } & \multicolumn{3}{|c|}{ Deterioration degree $C_{n}(\%)$} \\
\hline & & Extreme stress $(\mathrm{MPa})$ & Elastic modulus (GPa) & Poisson's ratio \\
\hline \multirow{4}{*}{0} & 0 & 0 & 0 & 0 \\
\hline & 2 & -244.49 & -10.08 & 0.77 \\
\hline & 4 & -364.59 & -30.00 & 1.92 \\
\hline & 6 & -487.85 & -30.87 & 2.30 \\
\hline \multirow{4}{*}{5} & 0 & 0 & 0 & 0 \\
\hline & 2 & -225.90 & -49.37 & 3.36 \\
\hline & 4 & -275.92 & -67.47 & 4.10 \\
\hline & 6 & -505.65 & -80.51 & 4.85 \\
\hline \multirow{4}{*}{10} & 0 & 0 & 0 & 0 \\
\hline & 2 & -234.24 & -51.91 & 3.32 \\
\hline & 4 & -397.63 & -69.38 & 4.06 \\
\hline & 6 & -518.92 & -74.11 & 4.43 \\
\hline \multirow{4}{*}{20} & 0 & 0 & 0 & 0 \\
\hline & 2 & -202.91 & -68.24 & 3.94 \\
\hline & 4 & -382.80 & -101.51 & 5.38 \\
\hline & 6 & -510.91 & -134.40 & 6.81 \\
\hline \multirow{4}{*}{40} & 0 & 0 & 0 & 0 \\
\hline & 2 & -220.21 & -37.86 & 1.07 \\
\hline & 4 & -418.66 & -78.06 & 2.86 \\
\hline & 6 & -544.47 & -80.97 & 3.93 \\
\hline
\end{tabular}

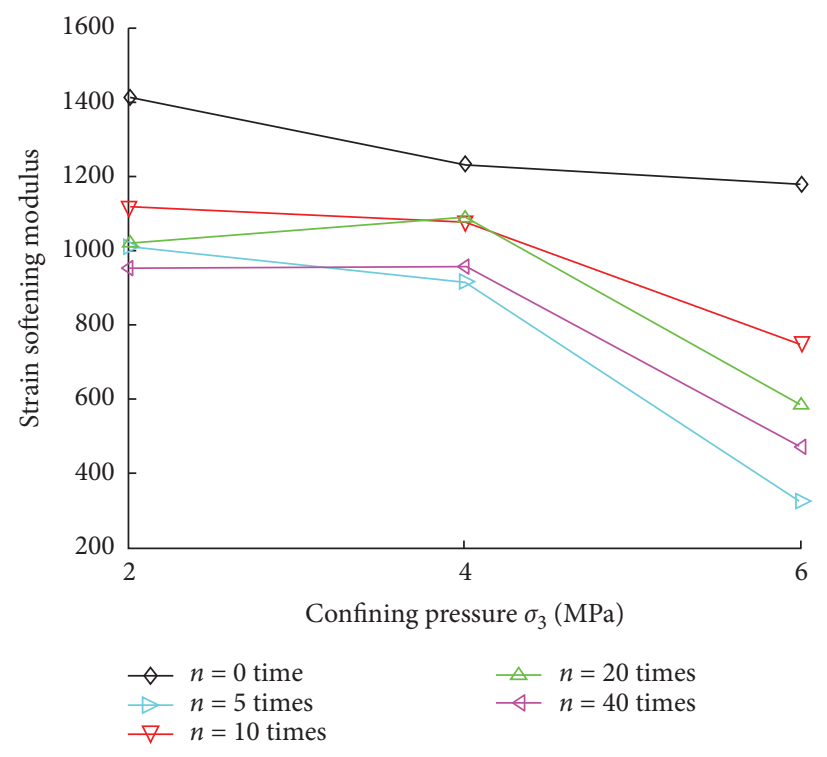

FiguRE 3: Effect of confining pressure on strain softening modulus.

\section{Determination of Damage Constitutive Relations and Parameters}

4.1. Establishment of Damage Constitutive Relation of Rock under Freeze-Thaw and Load. Due to the effect of freezethaw cycle and load, random distribution in rock internal microcracks and pores will continue to expand, showing the deterioration of rock macroscopic mechanical properties. When the change reaches a certain level, the material was destroyed. Therefore, the damage constitutive relation under the freeze-thaw and load must be established to explore the microstructural damage and reveal the mechanical nature of rock damage.

The existing rock damage models consider less freezethaw effect and have a greater limitation on its application in cold region. Therefore, in this paper, the total number of micromembers in the cold region was divided into three parts: freeze-thaw damage microelements, load damage microelements, and nondamage microelements. The rock was subjected to nominal stress $\sigma_{i}$, and the corresponding 


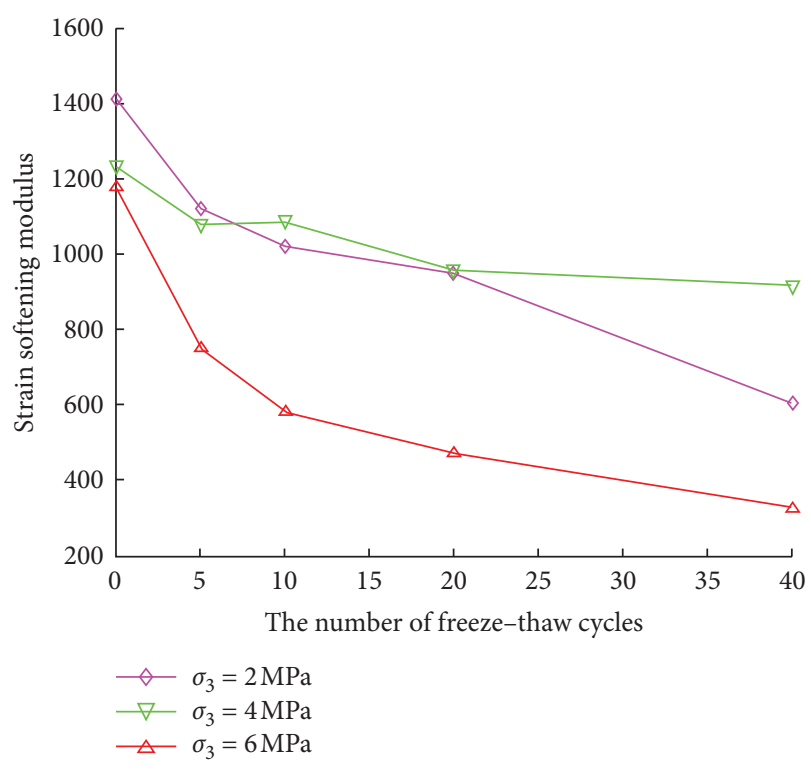

FIGURE 4: Effect of freeze-thaw cycle on strain softening modulus.

microelements were rock total microelements $N$, rock nondamage part subjected to effective stress $\sigma_{i}^{\prime}$, corresponding rock nondamage microelements $N_{1}$, and rock damage part subjected to residual stress $\sigma_{r}$. The corresponding microelements were rock damage microelements, including the number of freeze-thaw damage microelements $N_{n}$ and the number of loaded damage microelements $N_{d}$.

Assuming that the rock microelement area was $\Delta A$, by analyzing the microscopic forces and geometric conditions of various parts of rock, the following can be obtained:

$$
\sigma_{i} N \Delta A=\sigma_{i}^{\prime} N_{1} \Delta A+\sigma_{r}\left(N_{n} \Delta A+N_{d} \Delta A\right) .
$$

Starting from the aspect of rock microelement, the definition of freeze-thaw damage variable $D_{n}$ as the ratio of freeze-thaw damage microelements to total microelement of rock is as follows:

$$
D_{n}=\frac{N_{n}}{N}
$$

The final rock damage was composed of freeze-thaw damage and load damage. At this time, total damage variable $D$ can be defined as

$$
D=\frac{N_{n}+N_{d}}{N}
$$

Using (4)-(6), the following can be obtained:

$$
\sigma_{i}=\frac{\sigma_{i}^{\prime} N_{1}+\sigma_{r}\left(N_{n}+N_{d}\right)}{N}=\sigma_{i}^{\prime}(1-D)+\sigma_{r} D .
$$

It was assumed that the nondamage part of rock obeyed the generalized Hooke's law, and damage occurred only in the direction of the $\sigma_{1}$ principal stress, and the other two principal stress directions did not consider damage; that is, $\sigma_{2}=\sigma_{2}^{\prime}$ and $\sigma_{3}=\sigma_{3}^{\prime}$. According to the significance of Poisson's ratio of the petrophysical parameters and the deformation coordination relationship of various parts of rock, the following can be obtained under equal confining pressure conditions:

$$
\sigma_{1}^{\prime}=E_{n} \varepsilon_{1}^{\prime}+2 \mu_{n}^{\prime} \sigma_{3}=E_{n} \varepsilon_{1}+2 \mu_{n} \sigma_{3},
$$

where $\varepsilon_{1}^{\prime}$ and $\mu_{n}^{\prime}$ were rock undamaged part effective strain and effective Poisson's ratio; $E_{n}, \varepsilon_{1}$, and $\mu_{n}$ were rock elastic modulus, strain, and Poisson's ratio after $n$ times of freezethaw cycles.

Substituting (8) into (7), one can obtain the damage constitutive model about the $\sigma_{1}$ principal stress direction, expressed as follows:

$$
\sigma_{1}=\left(E_{n} \varepsilon_{1}+2 \mu_{n} \sigma_{3}\right)(1-D)+\sigma_{r} D
$$

The rock had been subjected to freeze-thaw cycles, resulting in a certain amount of pores and cracks inside the rock, which had a certain amount of damage and cannot be ignored. After that, under the action of load, nondamage microelements continued to be transformed into damage microelements. Due to the heterogeneity of rock in the mesostructure, the distribution of the mechanical properties of internal microelements was random. Therefore, it was assumed that the probability density function of load microelement damage is $P[F]$. So, the total damage variable can be expressed as

$$
D=\frac{D_{n} N+\int_{0}^{F}\left(N-N_{n}\right) P[x] \mathrm{d} x}{N}=D_{n}+\left(1-D_{n}\right) \int_{0}^{F} P[x] \mathrm{d} x,
$$

where $F$ was a random distribution variable of rock microelement strength.

Assuming that the rock microelement strength strength $F$ obeyed Weibull distribution, its probability density function can be expressed as

$$
P(F)=\frac{m}{F_{0}}\left(\frac{F}{F_{0}}\right)^{m-1} \exp \left[-\left(\frac{F}{F_{0}}\right)^{m}\right],
$$

where $F_{0}$ and $m$ were the model parameters.

Substituting (11) into (10), one can obtain the total damage variable of rock under the freeze-thaw and load, expressed as follows:

$$
D=1-\left(1-D_{n}\right) \exp \left[-\left(\frac{F}{F_{0}}\right)^{m}\right] .
$$

Substituting (12) into (9), the following can be obtained:

$$
\sigma_{1}=\left(1-D_{n}\right)\left(E_{n} \varepsilon_{1}+2 \mu_{n} \sigma_{3}-\sigma_{r}\right) \exp \left[-\left(\frac{F}{F_{0}}\right)^{m}\right]+\sigma_{r} \text {. }
$$

Equation (14) was the expression of rock damage constitutive model under freeze-thaw and load established in this paper. It can be seen from (14) that when $D_{n}=0$, (14) became the damage constitutive model at normal temperature.

Whether damage constitutive model can better reflect the deformation characteristics of rock or not, the key point was the reasonable measurement of the rock microelement 
strength. Therefore, if the rock microdestruction was assumed to obey the D-P criterion, the random distribution variable $F$ can be expressed as

$$
F=\alpha I_{1}^{\prime}+\sqrt{J_{2}^{\prime}}-K_{1},
$$

where $\quad \alpha=\sin \phi_{n} / \sqrt{9+3 \sin ^{2} \phi_{n}}, \quad K_{1}=\sqrt{3} \cdot c_{n} \cos \phi_{n} /$ $\sqrt{3+\sin ^{2} \phi_{n}}, c_{n}$ was the cohesion of rock under freeze-thaw, $\phi_{n}$ was the internal friction angle of rock under freeze-thaw, and $I_{1}^{\prime}$ and $J_{2}^{\prime}$ were effective stress tensor first invariant and effective stress bias second invariant, expressed as

$$
\begin{gathered}
I_{1}^{\prime}=\sigma_{1}^{\prime}+2 \sigma_{3}^{\prime}, \\
\sqrt{J_{2}^{\prime}}=\frac{1}{\sqrt{3}}\left(\sigma_{1}^{\prime}-\sigma_{3}^{\prime}\right) .
\end{gathered}
$$

According to the direction of $\sigma_{2}$ and $\sigma_{3}$, the principal stress did not cause damage. Substituting (8) into (15) and (16), respectively, the following can be obtained:

$$
\begin{gathered}
I_{1}^{\prime}=E_{n} \varepsilon_{1}+2 \mu_{n} \sigma_{3}+2 \sigma_{3}, \\
\sqrt{J_{2}^{\prime}}=\frac{1}{\sqrt{3}}\left(E_{n} \varepsilon_{1}+2 \mu_{n} \sigma_{3}-\sigma_{3}\right) .
\end{gathered}
$$

Using (14), (17), and (18), $F$ can be expressed as

$$
F=\left(\frac{\sqrt{3}}{3}+\alpha\right) E_{n} \varepsilon_{1}+\left[2\left(\frac{\sqrt{3}}{3}+\alpha\right) \mu_{n}+\left(2 \alpha-\frac{\sqrt{3}}{3}\right)\right] \sigma_{3}-K_{1} \text {. }
$$

4.2. Determination of Parameters. From the total damage variable expression of (12) and the damage constitutive model of (14), it can be seen that the determination of model parameters $m$ and $F_{0}$ was one of the key problems in model establishment. According to the geometric relationship at the peak point in the stress-strain curve of rock, the peak stress $\sigma_{s c}$ and the corresponding strain $\varepsilon_{s c}$ satisfy the following geometric conditions:
(a) $\varepsilon_{1}=\varepsilon_{s c}, \sigma_{1}=\sigma_{s c}$
(b) $\varepsilon_{1}=\varepsilon_{s c},\left(d \sigma_{1} / d \varepsilon_{1}\right)=0$

Substituting condition (a) into (13), the relationship between parameters $m$ and $F_{0}$ can be expressed as

$$
\exp \left[-\left(\frac{F_{s c}}{F_{0}}\right)^{m}\right]=\frac{\sigma_{s c}-\sigma_{r}}{\left(1-D_{n}\right)\left(E_{n} \varepsilon_{s c}+2 \mu_{n} \sigma_{3}-\sigma_{r}\right)},
$$

where $F_{s c}$ was the value of $F$ in (19) when $\varepsilon_{1}=\varepsilon_{s c}$.

Using (13) to obtain the partial differential and then using condition (b), another relation about $m$ and $F_{0}$ can be expressed as

$$
1-\left(\frac{\sqrt{3}}{3}+\alpha\right) \frac{m\left(E_{n} \varepsilon_{s c}+2 \mu_{n} \sigma_{3}-\sigma_{r}\right)}{F_{s c}}\left(\frac{F_{s c}}{F_{0}}\right)^{m}=0 .
$$

Through (20) and (21), model parameters $m$ and $F_{0}$ can be expressed as

$$
\begin{aligned}
m & =\frac{F_{s c}}{((\sqrt{3} / 3)+\alpha)\left(E_{n} \varepsilon_{s c}+2 \mu_{n} \sigma_{3}-\sigma_{r}\right) \ln \left(\left(1-D_{n}\right)\left(E_{n} \varepsilon_{s c}+2 \mu_{n} \sigma_{3}-\sigma_{r}\right) / \sigma_{s c}-\sigma_{r}\right)}, \\
F_{0} & =\frac{F_{s c}}{\left(\ln \left(\left(1-D_{n}\right)\left(E_{n} \varepsilon_{s c}+2 \mu_{n} \sigma_{3}-\sigma_{r}\right) / \sigma_{s c}-\sigma_{r}\right)\right)^{1 / m}} .
\end{aligned}
$$

\section{Damage Characteristic Analysis and Constitutive Model Verification}

5.1. Analysis of Damage Characteristic. Under the action of freeze-thaw, water-ice phase transformation and the uneven swelling of mineral cause the deterioration of the mechanical properties of rock, and macroscopic physical quantities were responses. The degree of rock damage can be measured by the change of elastic modulus; that is, the deterioration degree obtained by elastic modulus in this paper was used to represent freeze-thaw damage variable. Using the test data in Figure 2 and Table 1, the sandstone damage evolution curves under various confining pressures and freeze-thaw cycles were obtained according to (12), (19), (22), and (23), as shown in Figure 5.
It can be seen that the total damage evolution curves obtained in this paper showed a consistently increasing trend and always changed within the interval $[0,1]$. Compared with Figure 2, it can be seen that, within a certain range, with the increase of strain, the total damage evolution curve tended to be horizontal and did not change. The reason for this was that red sandstone did not show new damage at this stage, corresponding to stress-strain curve compaction and elastic deformation stage of Figure 2. With the further increase of strain, the red sandstone had new damage, and the damage evolution curve showed an increasing trend, and the slope of curve first increased and then decreased, corresponding to stress-strain curve plastic deformation stage and strain softening stage shown in Figure 2. When the strain reached 

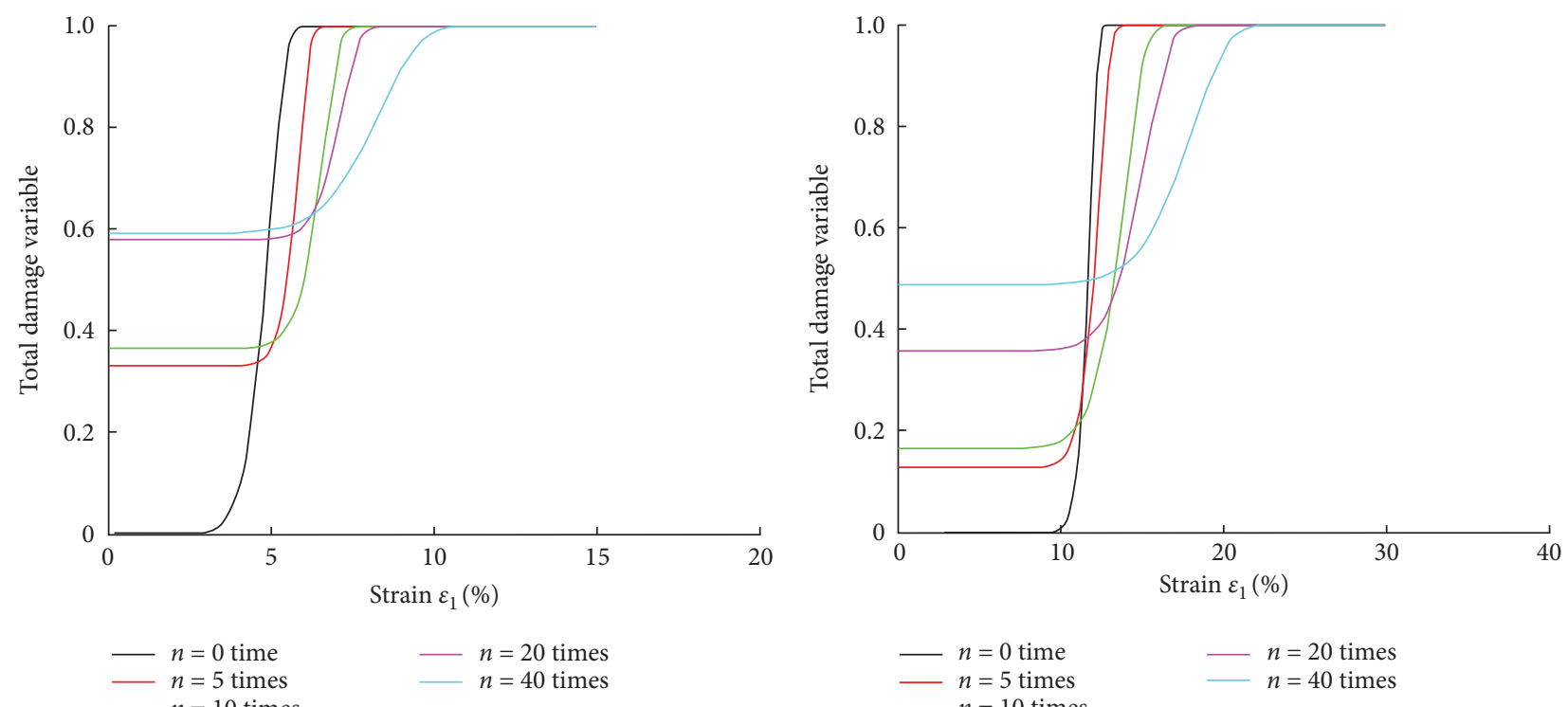

(a)

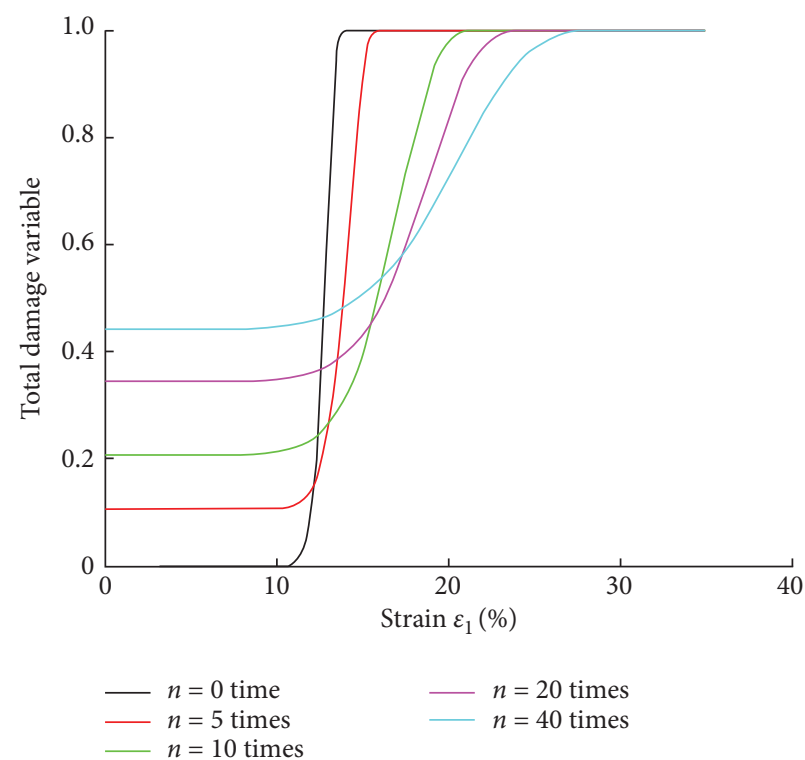

(c)

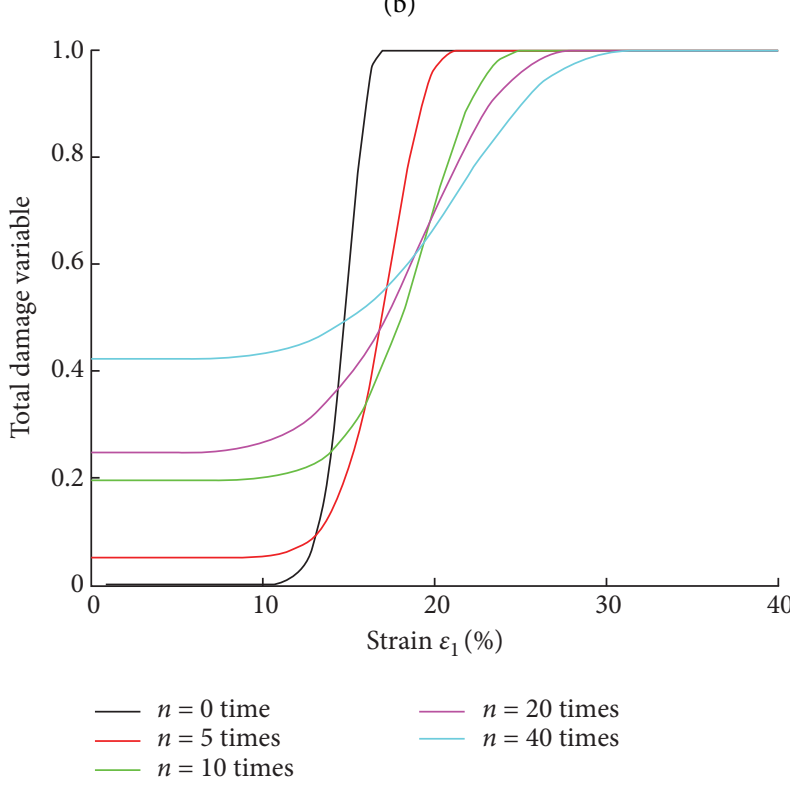

(d)

Figure 5: Total damage evolved curves on different confining pressures and freeze-thaw cycles of red sandstone. (a) $\sigma_{3}=0 \mathrm{MPa}$. (b) $\sigma_{3}=2 \mathrm{MPa}$. (c) $\sigma_{3}=4 \mathrm{MPa}$. (d) $\sigma_{3}=6 \mathrm{MPa}$.

a certain value, the red sandstone was completely destroyed, the total damage evolution curve developed horizontally, and the total damage variable was equal to 1 , corresponding to stress-strain curve residual stage shown in Figure 2. The law of red sandstone damage propagation was revealed by the trend of total damage evolution curves, which further indicated that the macroscopic mechanical properties predicted in this paper are consistent with the test results.
5.2. Verification of Model. Using the test data in Figure 2 and Table 1, and taking the confining pressure equal to 0 as an example, through formulas (13), (19), (22), and (23), the theoretical stress-strain curves under different freeze-thaw cycles were obtained, as shown in Figure 6. It can be seen that the theoretical curves of model were in good agreement with the test curves, which can better reflect the mechanical behavior of rock under various freeze-thaw cycles, thus verifying the rationality of the constitutive model. 


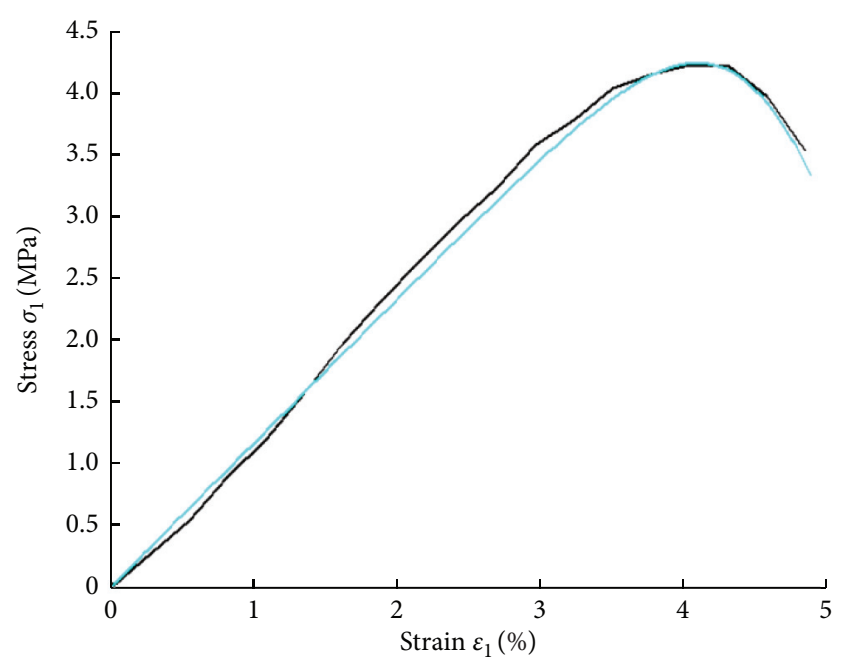

— Test curve

_ Theoretical curve

(a)

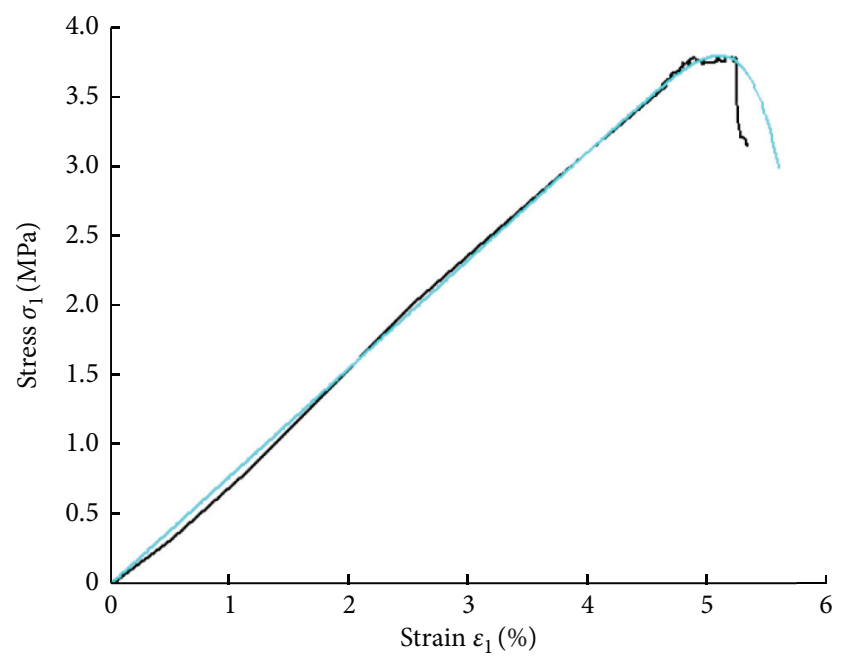

Test curve

Theoretical curve

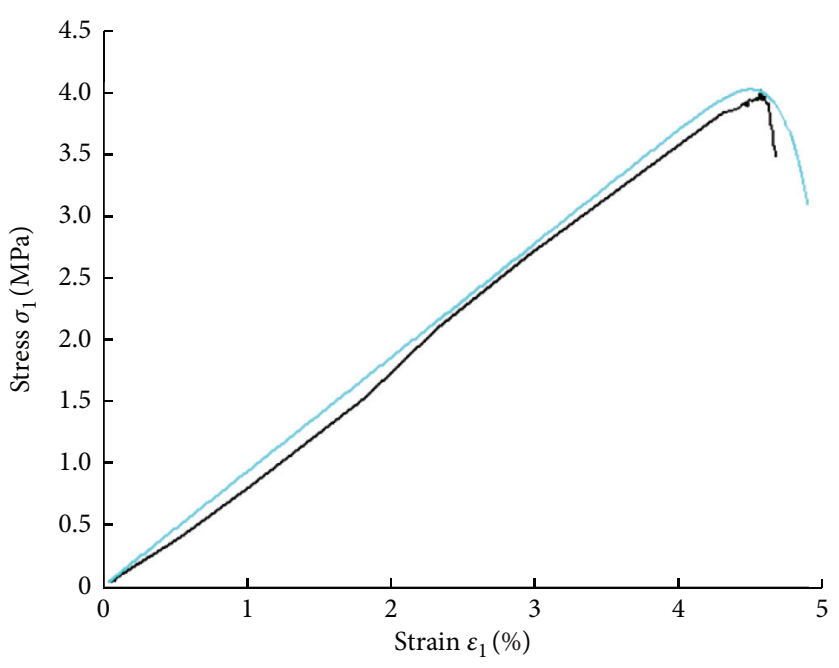

- Test curve

- Theoretical curve

(b)

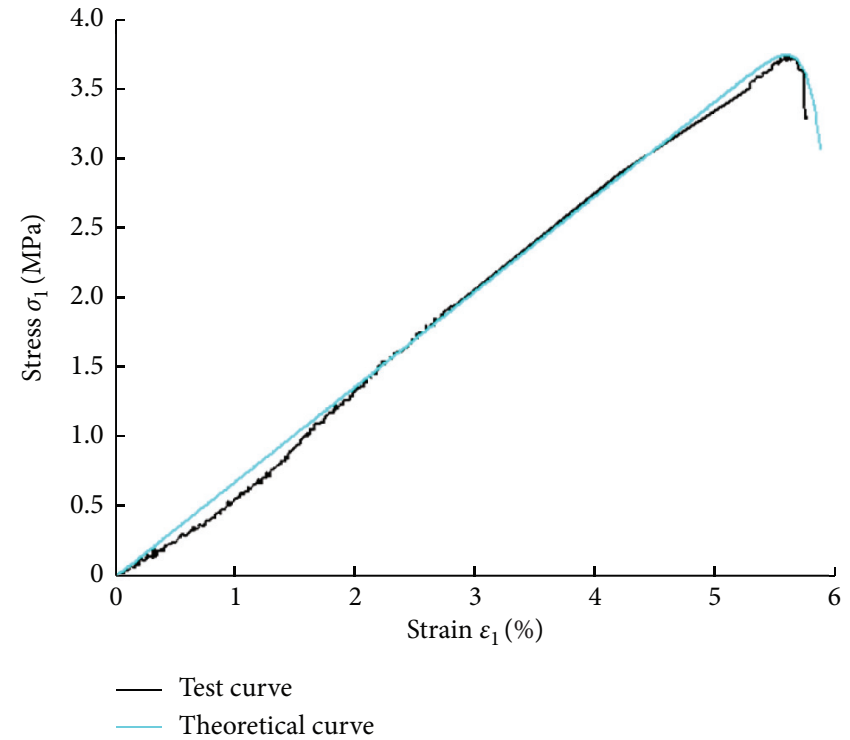

(d)

(c)

Figure 6: Continued. 


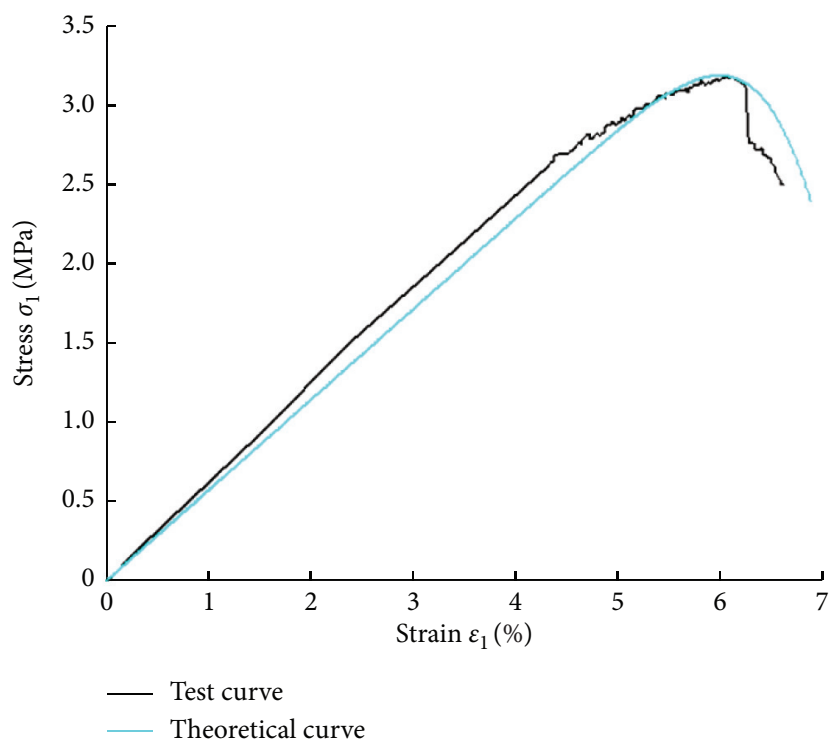

(e)

FiguRE 6: Verification of damage constitutive model for rock under different freeze-thaw cycles. (a) $n=0$. (b) $n=5$. (c) $n=10$. (d) $n=20$. (e) $n=40$.

\section{Conclusion}

(1) Through the freeze-thaw cycle and triaxial compression tests of red sandstone performed in this paper, the following can be known. With the increase of freeze-thaw cycles, the uneven shrinkage of red sandstone particles caused by freeze-thaw cycles and water-ice phase change intensified the damage deterioration, and this macroscopically showed the decrease of red sandstone stiffness and strength. With the increase of confining pressure, the growth rate of red sandstone damage gradually slowed down, and the plasticity characteristics increased in turn, and this macroscopically showed the increase of red sandstone stiffness and strength.

(2) By defining the reduction value of the mechanical parameters as deterioration degree, it is better to analyze the influence degree of freeze-thaw cycle and confining pressure on red sandstone. Under the action of freeze-thaw cycle and confining pressure, the difference in deterioration degree obtained by different mechanical parameters is relatively large. By defining the strain softening modulus, the strain softening degree under different confining pressures and different confining pressures is quantitatively considered. It can be seen that the increase of freezethaw cycles and the increase of confining pressure will lead to the enhancement of red sandstone plasticity.

(3) The comparison between the total damage evolution curve and the stress-strain curve obtained from the constitutive relationship established in this paper shows that the law of red sandstone damage propagation is revealed by the trend of the total damage evolution curve, and the damage evolution path of red sandstone reflects the mesomechanical response consistent with the macrodeformation and failure process.

\section{Data Availability}

The data used has been listed in the article.

\section{Conflicts of Interest}

The authors declare that they have no conflicts of interest.

\section{Acknowledgments}

The authors are grateful for the financial support from the National Natural Science Foundation of China (no. 11172232), Special Fund Project of Shaanxi Provincial Department of Education (19JK0521), and Research on the Mechanism of Coal Seam Rich Water and Key Technology of Grouting Reform in Yuhengbei District (no. 2020XAYJS05).

\section{References}

[1] D. Ma, H. Duan, W. Liu, X. Ma, and M. Tao, "Water-sediment two-phase flow inrush hazard in rock fractures of overburden strata during coal mining," Mine Water and the Environment, vol. 39, no. 2, pp. 308-319, 2020.

[2] G. Khanlari and Y. Abdilor, "Influence of wet-dry, freezethaw, and heat-cool cycles on the physical and mechanical properties of upper red sandstones in central Iran," Bulletin of Engineering Geology and the Environment, vol. 74, no. 4, pp. 1287-1300, 2014.

[3] S. Demirdag, "Effects of freezing-thawing and thermal shock cycles on physical and mechanical properties of filled and unfilled travertines," Construction and Building Materials, vol. 47, pp. 1395-1401, 2013. 
[4] D. Ma, H. Duan, X. Li, Z. Li, Z. Zhou, and T. Li, "Effects of seepage-induced erosion on nonlinear hydraulic properties of broken red sandstones," Tunnelling and Underground Space Technology, vol. 91, Article ID 102993, 2019.

[5] Z. Karaca, A. Hamdi Deliormanli, H. Elci, and C. Pamukcu, "Effect of freeze-thaw process on the abrasion loss value of stones," International Journal of Rock Mechanics and Mining Sciences, vol. 47, no. 7, pp. 1207-1211, 2010.

[6] Y. Huseyin, "Effect of freeze-thaw and thermal shock weathering on the physical and mechanical properties of an andesite stone," Bulletin of Engineering Geology and the Environment, vol. 70, no. 2, pp. 187-192, 2011.

[7] F. Bayram, "Predicting mechanical strength loss of natural stones after freeze-thaw in cold regions," Cold Regions Science and Technology, vol. 83-84, pp. 98-102, 2012.

[8] A. Momeni, Y. Abdilor, G. R. Khanlari et al., "The effect of freeze-thaw on physical and mechanical properties of granitoid hard rocks," Bulletin of Engineering Geology and the Environment, vol. 75, no. 4, pp. 1649-1656, 2015.

[9] J. L. Li, K. P. Zhou, and W. J. Liu, "Analysis of the effect of freeze-thaw cycles on the degradation of mechanical parameters and slope stability," Bulletin of Engineering Geology and the Environment, vol. 78, no. 2, pp. 1295-1296, 2017.

[10] M. H. Ghobadi and R. Babazadeh, "Experimental studies on the effects of cyclic freezing-thawing, salt crystallization, and thermal shock on the physical and mechanical characteristics of selected sandstones," Rock Mechanics and Rock Engineering, vol. 48, no. 3, pp. 1001-1016, 2015.

[11] G. Khanlari, R. Z. Sahamieh, and Y. Abdilor, "The effect of freeze-thaw cycles on physical and mechanical properties of upper red formation sandstones, central part of Iran," Arabian Journal of Geosciences, vol. 8, no. 8, pp. 5991-6001, 2015.

[12] P. Jihwan, U. H. Chang, and H. D. Park, "Changes in microstructrue and physical properties of rocks caused by artificial freeze-thaw action," Bulletin of Engineering Geology and the Environment, vol. 74, no. 2, pp. 555-565, 2014.

[13] J. Liu, C. L. Xu, and R. H. Wang, "Physical characteristics of sandstone under freeze-thaw cycles," Journal of Hydroelectric Engineering, vol. 35, no. 5, pp. 123-130, 2016.

[14] K. P. Zhou, J. L. Li, Y. J. Xu et al., "Experimental study of NMR characteristics in rock under freezing and thawing cycles," Chinese Journal of Rock Mechanics and Engineering, vol. 31, no. 4, pp. 731-737, 2012.

[15] L. Wen, X. B. Li, Q. H. Wu et al., "Dynamic strength of granite porphyry under freezing-thawing cycles," Chinese Journal of Rock Mechanics and Engineering, vol. 34, no. 7, pp. 1297-1306, 2015.

[16] X. D. Luo, N. Jiang, C. Q. Zuo, Z. Dai, and S. Yan, "Damage characteristics of altered and unaltered diabases subjected to extremely cold freeze-thaw cycles," Rock Mechanics and Rock Engineering, vol. 47, no. 6, pp. 1-11, 2014.

[17] J. Eslami, C. Walbert, A. L. Beaucour, A. Bourges, and A. Noumowe, "Influence of physical and mechanical properties on the durability of limestone subjected to freeze-thaw cycles," Construction and Building Materials, vol. 162, pp. 420-429, 2017.

[18] J. Yu, G. F. Fu, X. Chen, and X. Guo, "Experimental study on mechanical properties of sandstone after freezing-thawing cycles under triaxial confining pressure unloading," Chinese Journal of Rock Mechanics and Engineering, vol. 34, no. 10, pp. 2001-2009, 2015.

[19] J. Yu, X. Chen, H. Li, J.-W. Zhou, and Y.-Y. Cai, "Effect of freeze-thaw cycles on mechanical properties and permeability of red sandstone under triaxial compression," Journal of Mountain Science, vol. 12, no. 1, pp. 218-231, 2015.

[20] T. C. Chen, M. R. Yeung, and N. Mori, "Effect of water saturation on deterioration of welded tuff due to freeze-thaw action," Cold Regions Science and Technology, vol. 38, pp. 127-136, 2014.

[21] X. J. Tan, W. Z. Chen, J. P. Yang, and J. Cao, "Laboratory investigations on the mechanical properties degradation of granite under freeze-thaw cycle," Cold Regions Science and Technology, vol. 68, pp. 130-138, 2017.

[22] Y.-L. Chen, J. Ni, L.-H. Jiang, M.-L. Liu, P. Wang, and R. Azzam, "Experimental study on mechanical properties of granite after freeze-thaw cycling," Environmental Earth Sciences, vol. 71, no. 8, pp. 3349-3354, 2014.

[23] L. Wen, X. B. Li, H. Y. Tang, and L. Weng, "Study of physicomechanical characteristics of rock under different frozenthawed circle temperature range and its engineering application," Engineering Mechanics, vol. 34, no. 5, pp. 247-256, 2017.

[24] F. Gao, Q. L. Wang, H. W. Deng et al., "Coupled effects of chemical environments and freeze-thaw cycles on damage characteristics of red sandstone," Bulletin of Engineering Geology and the Environment, vol. 76, no. 4, pp. 1481-1490, 2016.

[25] W. X. Ding, T. Xu, H. Y. Wang, and J. P. Chen, "Experimental study of mechanical property of limestone under coupled chemical solution and freezing-thawing process," Chinese Journal of Rock Mechanics and Engineering, vol. 34, no. 5, pp. 979-985, 2015.

[26] T. Han, J. Shi, and X. Cao, "Fracturing and damage to sandstone under coupling effects of chemical corrosion and freeze-thaw cycles," Rock Mechanics and Rock Engineering, vol. 49, no. 11, pp. 4245-4255, 2016.

[27] X. Fang, J. Xu, and P. Wang, "Compressive failure characteristics of yellow sandstone subjected to the coupling effects of chemical corrosion and repeated freezing and thawing," Engineering Geology, vol. 233, no. 31, pp. 160-171, 2018.

[28] J. Ni, Y.-L. Chen, P. Wang, S.-R. Wang, B. Peng, and R. Azzam, "Effect of chemical erosion and freeze-thaw cycling on the physical and mechanical characteristics of granites," Bulletin of Engineering Geology and the Environment, vol. 76, no. 1, pp. 169-179, 2017.

[29] B. Fatih, "Predicting mechanical strength loss of natural stones after freeze-thaw in cold regions," Cold Regions Science and Technology, vol. 83, no. 7, pp. 98-102, 2012.

[30] Y. Cheng, H. Li, W. Wang, L. Li, and H. Wang, "Laboratory evaluation on the performance degradation of styrene-butadiene-styrene-modified asphalt mixture reinforced with basalt fiber under freeze-thaw cycles," Polymers, vol. 12, no. 5, p. 1092, 2020.

[31] G. Tan, W. Wang, Y. Cheng, Y. Wang, and Z. Zhu, "Establishment of complex modulus master curves based on generalized sigmoidal model for freeze-thaw resistance evaluation of basalt fiber-modified asphalt mixtures," Polymers, vol. 12, no. 8, p. 1698, 2020.

[32] X. Q. Yuan, H. Y. Liu, and J. P. Liu, "A damaging model of jointed rock under coupled action of freezing and thawing," Chinese Journal of Rock Mechanics and Engineering, vol. 34, no. 8, pp. 1602-1611, 2015.

[33] Q. Liu, S. Huang, Y. Kang, and X. Liu, “A prediction model for uniaxial compressive strength of deteriorated rocks due to freeze-thaw," Cold Regions Science and Technology, vol. 120, pp. 96-107, 2015. 
[34] H. M. Zhang and G. S. Yang, "Research on damage model of rock under coupling action of freeze-thaw and load," Chinese Journal of Rock Mechanics and Engineering, vol. 29, no. 3, pp. 471-476, 2010.

[35] S.-W. Zhou, C.-C. Xia, H.-B. Zhao, S.-H. Mei, and Y. Zhou, "Statistical damage constitutive model for rocks subjected to cyclic stress and cyclic temperature," Acta Geophysica, vol. 65, no. 5, pp. 893-906, 2017.

[36] S. Huang, Q. Liu, A. Cheng, and Y. Liu, "A statistical damage constitutive model under freeze-thaw and loading for rock and its engineering application," Cold Regions Science and Technology, vol. 145, pp. 142-150, 2018. 